\title{
Orthorexia Nervosa - It Is Time to Think About Abandoning the Concept of a Distinct Diagnosis
}

\author{
Adrian Meule ${ }^{1,2 *}$ and Ulrich Voderholzer ${ }^{1,2,3}$ \\ ${ }^{1}$ Department of Psychiatry and Psychotherapy, University Hospital, Ludwig Maximilian University of Munich, Munich, \\ Germany, ${ }^{2}$ Schoen Clinic Roseneck, Prien am Chiemsee, Germany, ${ }^{3}$ Department of Psychiatry and Psychotherapy, \\ University Hospital of Freiburg, Freiburg, Germany
}

Keywords: orthorexia nervosa, anorexia nervosa, bulimia nervosa, eating disorders, obsessivecompulsive disorder

\section{INTRODUCTION}

The term orthorexia nervosa (ON) refers to an obsessive focus on healthy eating (1). Proposed diagnostic criteria include a dietary theory or set of beliefs about healthy foods, exaggerated emotional distress in relationship to food choices that are perceived as unhealthy, and clinical impairment because of compulsive dietary behaviors and mental preoccupation (2). Although research on ON has been conducted for 20 years, its measurement and clinical value are still hotly debated. For example, it is not clear whether $\mathrm{ON}$ is actually a diagnostic entity that is distinct from established eating disorders and other mental disorders such as obsessive-compulsive disorder.

\section{MEASUREMENT OF ON}

The large majority of studies on ON have been based on a questionnaire measure called the ORTO-15 (3) or several short versions of it [e.g., (4-6)]. However, studies have shown consistently that this instrument has poor psychometric properties, the most prominent of which is its low internal reliability [e.g., (7-9)]. Thus, findings based on the ORTO-15 are inconsistent and hardly interpretable. Several other instruments have been developed [cf. (9)]. However, using these measures has not been recommended [e.g., Bratman's Orthorexia Test $(1)$; cf. $(8,9)$ ] or they have only been used in a handful of studies yet [e.g., the Eating Habits Questionnaire (10) or the Orthorexia Nervosa Inventory (11); cf. $(9,12)]$. A relatively new measure with sound psychometric properties and which is increasingly used internationally (13-16) is the Düsseldorf Orthorexia Scale [DOS; (17)]. Therefore, we focus on studies that used the DOS in this opinion piece.

\section{OVERLAPS AND DIFFERENCES BETWEEN ON AND EATING DISORDERS}

Received: 11 December 2020 Accepted: 07 January 2021

Published: 28 January 2021

Citation:

Meule A and Voderholzer U (2021)

Orthorexia Nervosa-It Is Time to

Think About Abandoning the Concept

of a Distinct Diagnosis.

Front. Psychiatry 12:640401.

doi: 10.3389/fpsyt.2021.640401

A key feature of $\mathrm{ON}$ is that food choices are based on qualitative, health-related aspects of foods. That is, unlike in persons with anorexia nervosa, food choices are not based on quantitative, energy density-related aspects of foods that are motivated by a drive for thinness and body dissatisfaction. Specifically, Cena et al. (12) argue that-while established eating disorders and ON share common characteristics such as a concern over food and eating-ON is marked by open, rationalized rules related to eating and a focus on the quality of foods instead of fears of gaining weight and body image disturbances. Unlike eating disorders, which are more prevalent in females than males, conceptualizations of ON do also assume that there is no sex difference in orthorexic symptomatology (12). However, most studies that used the DOS could not demonstrate that 
orthorexic symptoms are independent from features of disordered eating behavior. For example, positive correlations between DOS scores and eating disorder symptoms such as drive for thinness and body dissatisfaction have been found in both non-clinical and clinical samples [e.g., (18-20)] and orthorexic symptomatology tends to be higher in females than males [e.g., (21)].

In line with these reports, we found that prevalence rates of ON (based on DOS scores of $\geq 30$ ) were high in inpatients with anorexia nervosa (48\%) and bulimia nervosa $(33 \%)$ in a recent study that tested a large sample of inpatients with mental disorders (22). Furthermore, DOS scores significantly decreased from admission to discharge, although orthorexic eating was not targeted in the eating disorder-specific treatment. Finally, higher DOS scores strongly related to higher drive for thinness and higher body dissatisfaction in these groups $(r \geq 0.5)$. Thus, our findings speak against the notion that $\mathrm{ON}$ represents a distinct diagnostic entity and suggest that it may rather be an aspect of restrictive eating disorder symptomatology.

\section{OVERLAPS AND DIFFERENCES BETWEEN ON AND OBSESSIVE-COMPULSIVE DISORDER}

Cena et al. (12) not only discuss similarities and differences between $\mathrm{ON}$ and eating disorders but also between $\mathrm{ON}$ and obsessive-compulsive disorder. Specifically, they highlight rigidity, perfectionism, and other obsessive-compulsive features as common characteristics while the only difference being that obsessive-compulsive symptoms relate to food and eating in $\mathrm{ON}$. Similarly, other authors have described the rigid beliefs about healthy eating as a form of obsessive thoughts and the avoidance of subjectively perceived unhealthy foods as a form of compulsive behavior [e.g., (23)] and higher DOS scores indeed relate to higher obsessive-compulsive symptoms [e.g., (24)].

In our study in inpatients with mental disorders (22), however, we did not find a substantial overlap between $\mathrm{ON}$ and mental disorders other than eating disorders. That is, the prevalence of $\mathrm{ON}$ (based on DOS scores of $\geq 30$ ) was similar to prevalence rates reported in the general population $[0-3 \%$; e.g., $(17,20,21)]$ in groups of patients with a depressive episode, recurrent depressive disorder, phobic disorders, obsessive-compulsive disorder, trauma-related disorders, and somatoform disorders. Unlike the changes observed in patients with eating disorders, DOS scores did not change from admission to discharge in these groups. Thus, this study showed a clear distinction from other mental disorders

\section{REFERENCES}

1. Bratman S, Knight D. Health Food Junkies. Orthorexia Nervosa: Overcoming the Obsession With Healthful Eating. New York, NY: Broadway Books (2000)

2. Dunn TM, Bratman S. On orthorexia nervosa: a review of the literature and proposed diagnostic criteria. Eating Behav. (2016) 21:11-7. doi: 10.1016/j.eatbeh.2015.12.006 such as obsessive-compulsive disorder, which is in line with other reports (25).

\section{DISCUSSION}

We conclude that-although orthorexic symptoms seem to be distinct from mental disorders such as obsessive-compulsive disorder-this distinction does not hold for established eating disorder diagnoses. Although features of eating disorders such as drive for thinness, body dissatisfaction, and sex differences are not part of ON conceptually, the independence of orthorexic symptomatology from these features could not be demonstrated empirically. To put our results into perspective, however, we also need to mention that DOS scores were unrelated to features of disordered eating in two studies from China $(15,26)$, indicating that there might be cultural differences in orthorexic symptomatology or in its measurement. Cultural differencesbetween China and Western countries in particular-have been previously noted in self-report measures of eating behavior and their correlates with the reasons for these differences remaining elusive $(27,28)$. Thus, we cannot exclude that the current evaluation about the ON construct is limited to Western (particularly European) countries, in which the majority of studies were conducted.

As a final remark, we argue that future research on $\mathrm{ON}$ requires more sophisticated approaches than cross-sectional questionnaire studies. For example, large interview-based studies seem to be necessary to gain deeper insights into the $\mathrm{ON}$ construct. Such studies may include applying structured clinical interviews such as the SCID-5-RV (29) and additionally the DOS or, preferably, a newly developed ON-specific interview. Only when individuals show an orthorexic eating behavior (e.g., as indicated by DOS scores $\geq 30$ ) that is accompanied by a clinical impairment or subjective distress and at the same time do not receive an established eating disorder diagnosis (which not only includes anorexia nervosa and bulimia nervosa but also any of the other eating disorder diagnoses listed in the DSM-5 or ICD-11), then a distinct diagnosis of ON may be justified. As results from empirical studies indicate, however, we would expect that such cases are rarely found (or may not be found at all) in the general population.

\section{AUTHOR CONTRIBUTIONS}

UV conceived the topic and proposition of this manuscript. AM wrote the first draft. Both authors contributed to revision of the manuscript.

4. Arusoglu G, Kabakçi E, Köksal G, Merdol TK. Orthorexia nervosa and adaptation of ORTO-11 into Turkish. Turkish J Psychiatry. (2008) 19:283-91.

5. Missbach B, Hinterbuchinger B, Dreiseitl V, Zellhofer S, Kurz C, König J. When eating right, is measured wrong! a validation and critical 
examination of the ORTO-15 questionnaire in German. PLoS ONE. (2015) 10:e0135772. doi: 10.1371/journal.pone.0135772

6. Rogoza R, Donini LM. Introducing ORTO-R: a revision of ORTO-15. Eat Weight Disord. (2020). doi: 10.1007/s40519-020-00924-5. [Epub ahead of print].

7. Meule A, Holzapfel C, Brandl B, Greetfeld M, Hessler-Kaufmann JB, Skurk $\mathrm{T}$, et al. Measuring orthorexia nervosa: a comparison of four self-report questionnaires. Appetite. (2020) 146:104512. doi: 10.1016/j.appet.2019.104512

8. Missbach B, Dunn TM, König JS. We need new tools to assess orthorexia nervosa. A commentary on "Prevalence of Orthorexia Nervosa among College Students Based on Bratman's Test and Associated Tendencies”. Appetite. (2017) 108:521-4. doi: 10.1016/j.appet.2016.07.010

9. Opitz M-C, Newman E, Alvarado Vázquez Mellado AS, Robertson MDA, Sharpe H. The psychometric properties of orthorexia nervosa assessment scales: a systematic review and reliability generalization. Appetite. (2020) 155:104797. doi: 10.1016/j.appet.2020.104797

10. Gleaves DH, Graham EC, Ambwani S. Measuring “orthorexia”: development of the eating habits questionnaire. Int J Educ Psychol Assess. (2013) 12:1-18.

11. Oberle CD, De Nadai AS, Madrid AL. Orthorexia Nervosa Inventory (ONI): development and validation of a new measure of orthorexic symptomatology. Eat Weight Disord. (2020). doi: 10.1007/s40519-020-00896-6. [Epub ahead of print].

12. Cena H, Barthels F, Cuzzolaro M, Bratman S, Brytek-Matera A, Dunn $\mathrm{T}$, et al. Definition and diagnostic criteria for orthorexia nervosa: a narrative review of the literature. Eating Weight Disorders. (2019) 24:20946. doi: 10.1007/s40519-018-0606-y

13. Brytek-Matera A. The Polish version of the Düsseldorf Orthorexia Scale (PLDOS) and its comparison with the English version of the DOS (E-DOS). Eat Weight Disord. (2020). doi: 10.1007/s40519-020-01025-z. [Epub ahead of print].

14. Chard CA, Hilzendegen C, Barthels F, Stroebele-Benschop N. Psychometric evaluation of the English version of the Düsseldorf Orthorexie Scale (DOS) and the prevalence of orthorexia nervosa among a U.S. student sample. Eating Weight Disorders. (2019) 24:275-81. doi: 10.1007/s40519-018-0570-6

15. He J, Ma H, Barthels F, Fan X. Psychometric properties of the Chinese version of the Düsseldorf Orthorexia Scale: prevalence and demographic correlates of orthorexia nervosa among Chinese University students. Eating Weight Disorders. (2019) 24:453-63. doi: 10.1007/s40519-019-00656-1

16. Parra-Fernández ML, Onieva-Zafra MD, Fernández-Muñoz JJ, FernándezMartínez E. Adaptation and validation of the Spanish version of the DOS questionnaire for the detection of orthorexic nervosa behavior. PLOS ONE. (2019) 14:e0216583. doi: 10.1371/journal.pone.0216583

17. Barthels F, Meyer F, Pietrowsky R. Die Düsseldorfer Orthorexie Skala-Konstruktion und Evaluation eines Fragebogens zur Erfassung ortho-rektischen Ernährungsverhaltens [Duesseldorf Orthorexia ScaleConstruction and evaluation of a questionnaire measuring orthorexic eating behavior]. Zeitschrift für Klinische Psychol Psychotherap. (2015) 44:97-105. doi: 10.1026/1616-3443/a000310

18. Barthels F, Kisser J, Pietrowsky R. Orthorexic eating behavior and body dissatisfaction in a sample of young females. Eat Weight Disord. (2020). doi: 10.1007/s40519-020-00986-5. [Epub ahead of print].
19. Barthels F, Meyer F, Huber T, Pietrowsky R. Analyse des orthorektischen Ernährungsverhaltens von Patienten mit Essstörungen und mit Zwangsstörungen [Analysis of orthorexic eating behavior in patients with eating disorders and obsessive-compulsive disorder]. Zeitschrift für Klinische Psychol Psychotherap. (2017) 46:32-41. doi: 10.1026/1616-3443/a000399

20. Brytek-Matera A, Onieva-Zafra MD, Parra-Fernández ML, Staniszewska A, Modrzejewska J, Fernández-Martínez E. Evaluation of orthorexia nervosa and symptomatology associated with eating disorders among European University students: a multicentre cross-sectional study. Nutrients. (2020) 12:3716. doi: 10.3390/nu12123716

21. Greetfeld M, Hessler-Kaufmann JB, Brandl B, Skurk T, Holzapfel C, Quadflieg $\mathrm{N}$, et al. Orthorexic tendencies in the general population: association with demographic data, psychiatric symptoms, and utilization of mental health services. Eat Weight Disord. (2020). doi: 10.1007/s40519-020-00961-0. [Epub ahead of print].

22. Hessler-Kaufmann JB, Meule A, Greetfeld M, Schlegl S, Voderholzer U. Orthorexic tendencies in inpatients with mental disorders. J Psychosomatic Res. (2021) 140:110317. doi: 10.1016/j.jpsychores.2020.110317

23. Zickgraf HF. Treatment of pathologic healthy eating (orthorexia nervosa). In: Storch EA, McKay D, Abramowitz JS, editors. Advanced Casebook of Obsessive-Compulsive and Related Disorders. Cambridge, MA: Academic Press. (2020) p. 21-40. doi: 10.1016/B978-0-12-816563-8.00002-4

24. Strahler J, Hermann A, Walter B, Stark R. Orthorexia nervosa: a behavioral complex or a psychological condition? J Behav Addict. (2018) 7:114356. doi: 10.1556/2006.7.2018.129

25. Bartel SJ, Sherry SB, Farthing GR, Stewart SH. Classification of orthorexia nervosa: further evidence for placement within the eating disorders spectrum. Eating Behav. (2020) 38:101406. doi: 10.1016/j.eatbeh.2020.101406

26. He J, Zhao Y, Zhang H, Lin Z. Orthorexia nervosa is associated with positive body image and life satisfaction in Chinese elderly: evidence for a positive psychology perspective. Int J Eat Disord. (2020). doi: 10.1002/eat.23400. [Epub ahead of print].

27. Meule A. Cultural reflections on restrained eating. Front Psychol. (2016) 7: 205. doi: 10.3389/fpsyg.2016.00205

28. Meule A. Cross-cultural testing of dietary restraint. In: Meiselman H, editor. Handbook of Eating and Drinking: Interdisciplinary Perspectives. Heidelberg: Springer. (2019). doi: 10.1007/978-3-319-75388-1_134-1

29. First MB. Structured Clinical Interview for the DSM (SCID). In: Cautin RL, Lilienfeld SO, editors. The Encyclopedia of Clinical Psychology. Indianaplis, IN: John Wiley \& Sons, Inc. (2015). doi: 10.1002/9781118625392.wbecp351

Conflict of Interest: The authors declare that the research was conducted in the absence of any commercial or financial relationships that could be construed as a potential conflict of interest.

Copyright (C) 2021 Meule and Voderholzer. This is an open-access article distributed under the terms of the Creative Commons Attribution License (CC BY). The use, distribution or reproduction in other forums is permitted, provided the original author(s) and the copyright owner(s) are credited and that the original publication in this journal is cited, in accordance with accepted academic practice. No use, distribution or reproduction is permitted which does not comply with these terms. 